\title{
Biodiesel from Citrus reticulata (mandarin orange) seed oil, a potential non-food feedstock.
}

\begin{abstract}
Oil extracted from Citrus reticulata (mandarin orange) seeds was investigated as a potential feedstock for the production of biodiesel. The biodiesel fuel was prepared by sodium methoxide-catalyzed transesterification of the oil with methanol. Fuel properties that were determined include cetane number, cloud, pour, and cold filter plugging points, kinematic viscosity, oxidative stability, flash point, sulfur content, ash content, density and acid value. The citrus seed oil methyl esters were found to satisfy both ASTM D6751 and EN 14214 biodiesel standards. The NMR spectra of the methyl esters of C. reticulata seed oil are reported.
\end{abstract}

Keyword: Biodiesel; Citrus reticulata; Fuel properties; Methylesters 